\title{
Correction to: New Information About Manifestations of Spin Exchange in the EPR Spectra of Solutions of Paramagnetic Particles Under Saturation Conditions
}

\section{K. M. Salikhov ${ }^{1}$}

Published online: 20 November 2021

(c) Springer-Verlag GmbH Austria, part of Springer Nature 2021

\section{Correction to: Applied Magnetic Resonance https://doi.org/10.1007/s00723-021-01364-9}

In the print published article, Eqs. (21) and (22) were published incorrectly. The correct equations are given below.

$$
\begin{gathered}
\Omega=a / 2, \\
\Delta \omega_{1 / 2}=\left(1 / T_{2}\right)\left(1+\omega_{1}^{2} T_{1} T_{2}\right)^{1 / 2} . \\
\Omega=(1 / 2)\left(a^{2}-V^{2}\right)^{1 / 2}, \\
\Delta \omega_{1 / 2}=1 / T_{2}+V / 2 .
\end{gathered}
$$

Publisher's Note Springer Nature remains neutral with regard to jurisdictional claims in published maps and institutional affiliations.

The original article can be found online at https://doi.org/10.1007/s00723-021-01364-9.

K. M. Salikhov

kevsalikhov@mail.ru

1 Zavoisky Physical-Technical Institute, Federal Research Center "Kazan Scientific Center of Russian Academy of Sciences”, Sibirsky Trakt Str, 10/7, Kazan 420029, Tatarstan Republik, Russian Federation 